\title{
P76 Carotid Artery Disease in Patients with Newly Diagnosed, Untreated Familial Hypercholesterolemia
}

\author{
Bíborka Nádró, Beáta Kovács, Ágnes Diószegi, Lilla Juhász, Dénes Páll, György Paragh, Mariann Harangi* \\ Department of Internal Medicine, University of Debrecen Faculty of Medicine, Debrecen, Hungary
}

\begin{abstract}
Familial hypercholesterolemia (FH) patients are characterized by markedly elevated LDL-cholesterol (LDL-C) concentration, positive family history of hypercholesterolemia and premature vascular complications including carotid artery disease (CAAD). Carotid plaques are associated with atherosclerosis of coronary arteries and might be considered as a useful prognostic marker in coronary events. Sixty-six newly diagnosed, untreated patients with heterozygous familial hypercholesterolemia (21 males, 45 females, mean age: $54.2 \pm 13$ years) were enrolled. Serum lipid parameters were measured and documentations on previous carotid artery ultrasound examinations were evaluated. FH was diagnosed using Dutch Lipid Network Criteria. Mean total cholesterol level was $8.19 \pm 1.7 \mathrm{mmol} / \mathrm{L}$, mean LDL-C level was $5.94 \pm 1.6 \mathrm{mmol} / \mathrm{L}$, while mean HDL-C was $1.65 \pm 0.5 \mathrm{mmol} / \mathrm{L}$ in FH patients. Median of lipoprotein (a) was $118 \mathrm{mg} / \mathrm{dL}$. Documentation on carotid artery ultrasound examination was available in 25 cases (41.7\%). Among them, significant stenosis was found in 11 cases (44\%), while intimal sclerosis was described in 9 patients (36\%). Altogether, carotid artery atherosclerosis was documented in 20 cases (80\%), while the ultrasound findings were negative in 5 cases (20\%). Based on these results, carotid artery ultrasound examination is not a commonly used screening method in severe hypercholesterolemic patients, unfortunately. When it was performed, CAAD was found in most of our FH patients. Therefore, carotid artery ultrasound should be indicated in all patients with severe hypercholesterolemia. Screening for CAAD in this population could help in risk stratification and treatment. This research was supported by a grant from the National Research, Development and Innovation (NFKI) (OTKA 115723) and by the GINOP-2.3.2-15-2016-00062 project.
\end{abstract}

(c) 2019 Association for Research into Arterial Structure and Physiology. Publishing services by Atlantis Press International B.V. This is an open access article distributed under the CC BY-NC 4.0 license (http://creativecommons.org/licenses/by-nc/4.0/). 